\title{
ELEMENTO SUBJETIVO DOS ATOS DE IMPROBIDADE ADMINISTRATIVA: A (IN) APLICABILIDADEDA CULPA E DO DOLO ${ }^{1}$
}

\section{The subjective element of the acts of administrative misconduct: The in(applicability) of negligence and willful misconduct}

\section{Leonardo Marcio Laureano²}

Resumo: Os princípios regentes da Administração Pública na Constituição da República Federativa do Brasil têm, dentre as medidas protetivas à sua concretização, o comando constitucional de punição dos atos de improbidade administrativa, na forma da Lei $\mathrm{n}^{\circ}$ 8.429/1992. Todavia, determinados elementos atinentes à disciplina têm ensejado certa controvérsia na doutrina e na jurisprudência, como o elemento subjetivo necessário à sua configuração, se culposo e/ou doloso. Nesse sentido,
Abstract: The ruling principles of Public Administration in the Constitution of the FederativeRepublic of Brazil have, among the protective measuresforitsimplementation, the constitutional command of punishing acts of administrative misconduct, according to Law $n^{\circ}$ 8.429/1992. However, certain elements regarding the discipline have occasioned some controversy in doctrine and jurisprudence, like the subjective element necessary to its setting, if by fault and/ or a willful misconduct. In

1 Artigo originalmente apresentado como Trabalho de Conclusão no Curso de PósGraduação em Direito Público pela Universidade Anhanguera (Uniderp) em parceria com a Rede de Ensino Luiz Flávio Gomes (LFG).

2 Bacharel em Direito pela Universidade Federal de Santa Catarina (UFSC). Bacharel em Administração Empresarial pela Universidade do Estado de Santa Catarina (UDESC/ESAG). Especialista em Direito Público pela Universidade Anhanguera (Uniderp) em parceria com a Rede de Ensino Luiz Flávio Gomes (LFG). Assessor Jurídico em Gabinete de Desembargador no Tribunal de Justiça de Santa Catarina (TJSC). E-mail: leonardomlaureano@gmail.com 
a fim de definir tal premissa, o presente estudo parte da compreensão do conceito de improbidade administrativa sob as concepções enraizadas na Constituição, de modo a extrair quais as espécies de práticas atentatórias à Administração Pública que teve o legislador constituinte e, por consequência, também o infraconstitucional, o objetivo de punir, notadamente a partir da noção distintiva entre os conceitos de legalidade, moralidade e probidade. Na sequência, perpassam-se as modalidades de atos de improbidade administrativa, tal como previstos nos arts. $9^{\circ}, 10$ e 11 da Lei $n^{\circ} 8.429 / 1992$, permitindo-se, assim, compreender a extensão concretizada da temática. E, por fim, inclinando-se ao ponto nodal da discussão, à luz das premissas anteriormente delineadas, promove-se o exame dos elementos subjetivos admissíveis à configuração da improbidade administrativa.

Palavras-chave: Improbidade administrativa. Elemento subjetivo. Culpa. Dolo. this regard, in order to define such a premise, this study lies on the understanding of the concept of administrative misconduct under conceptions rooted in the Constitution, in order to extract what kinds of practices prejudicial to public administration had the legislators towards the punishment, from the distinctive notion of the concepts of legality, morality and probity. Next, the procedures for acts of administrative misconduct, as set out in articles $9^{\text {th }}, 10$ and 11 of Law $n^{\circ}$ 8.429/1992, are appraised, thus allowing to understand the extent of the subject. Finally, leaning to the nodal point of discussion, in the light of the previously outlined assumptions, the examination of the subjective elements acceptable to the configuration of administrative misconduct are examined.

Keywords: Administrative misconduct. Subjective element. Fault. WillfulMisconduct.

\section{INTRODUÇÃO}

O fenômeno da corrupção está presente na sociedade brasileira desde os seus primórdios, ainda que em níveis e ramos diferenciados. Apesar de ser realidade há muito existente, junto 
da evolução da prática, também tem crescido o ânimo pela punição dos corruptos, bem como os mecanismos disponíveis a tanto, com ampliação dos estudos doutrinários e, igualmente, das aplicações práticas, formando-se jurisprudência na temática. Isso se justifica, pois a corrupção pública é responsável pela promoção do desvirtuamento da Administração, violando preceitos estruturantes do ordenamento jurídico.

Nesse sentido, uma série de princípios regentes da Administração Pública foi estabelecida, a partir de 1988, na Constituição da República Federativa do Brasil. Dentre as medidas previstas pelo próprio texto constitucional, a fim de concretizar e preservar tais preceitos, encontra-se o comando, no art. 37, $\S 4^{\circ}$, de que atos de improbidade administrativa deverão ser punidos, em força e gradação a serem definidas em lei. Assim, criou-se a Lei no 8.429/1992, que disciplina, essencialmente, os atos de improbidade administrativa, os seus requisitos configuradores e as respectivas sanções aplicáveis.

Contudo, a despeito da maior regulamentação da temática, algumas disposições constantes da Lei no 8.429/1992 têm ensejado certa controvérsia doutrinária e jurisprudencial, dificultando a efetivação da finalidade maior incutida na punição dos atos de improbidade administrativa e dos agentes ímprobos, qual seja, resguardar os princípios regentes da Administração Pública.

Dentre as temáticas questionadas, tem-se o elemento subjetivo dos atos de improbidade administrativa, questão que não resta pacificada, com variações de aceitação do tipo subjetivo de um ato de improbidade para o outro, residindo, no ponto, a problemática que o presente estudo pretende aclarar, para melhor compreender o caminho a ser trilhado, a fim de efetivar as razões pelas quais punidas tais práticas ilícitas.

Sob esse prisma, a pesquisa ora apresentada dedica-se, inicialmente, a incursionar acerca dos aspectos conceituais que fundamentam o sancionamento previsto ao instituto da improbidade administrativa. Na sequência, promove-se a exposição 
dos principais aspectos descritivos das modalidades de atos de improbidade administrativa consagrados nos arts. 9०, 10 e 11 da Lei no 8.429/1992. Por fim, atingindo o cerne da discussão, analisa-se a admissibilidade dos elementos subjetivos cabíveis à configuração dos atos de improbidade administrativa, nas feições culposa e dolosa, em suas diferentes modalidades.

\section{CONCEITO DE IMPROBIDADE ADMINISTRATIVA}

O vocábulo probidade, em digressão por sua raiz etimológica, vem do latim probitate, que significa aquilo que é bom, honrado, honesto, íntegro. Noutro vértice, improbidade deriva do latim improbitate, que significa imoralidade, desonestidade (NEVES; OLIVEIRA, 2014).

Em suas lições, Antonio Carlos Alves Braga (1994 apud FIGUEIREDO, 2010, p. 43) afirma que improbo "é o homem mau, perverso, enganador, corrupto, devasso, desonesto, falso", concluindo, assim, que a improbidade "é atributo negativo da personalidade e do caráter".

Em seu tradicional escólio, Oscar Joseph de Plácido e Silva (1987, p. 799) doutrina, com a propriedade habitual, que improbidade,

[...] juridicamente, liga-se ao sentido de desonestidade, má fama, incorreção, má conduta, má índole, mau caráter. Desse modo, improbidade revela a qualidade do homem que não procede bem, por não ser honesto, que age indignamente, por não ter caráter, que não atua com decência, por ser amoral.

A probidade administrativa, por sua vez, é concepção que, uma vez ligada à Administração Pública, transcende à moral genérica, escorando-se, também, na moral jurídica, ou seja, enraíza-se nos princípios gerais de direito (ROCHA, 2000). Dessa forma, a improbidade administrativa é a violação não apenas de um dever moral, mas também de um dever legal, 
eis que, além de serem práticas desonestas, imbuídas de má-fé, deslealdade, corrupção e perversão, também maculam uma disposição normativa consagrada no ordenamento jurídico (FIGUEIREDO, 2010).

Nessa vereda, bem ensina Diogo de Figueiredo Moreira Neto $(2009$, p. 105) que, "enquanto a moral comum é orientada por uma distinção puramente ética, entre o bem e o mal, distintamente, a moral administrativa é orientada por uma diferença prática entre a boa e a má administração”, afinal, inegável é o liame entre a moralidade e o bom administrador, sendo este aquele que compreende a linha distintiva entre o lícito e o ilícito, o justo e o injusto (NEVES; OLIVEIRA, 2014).

A improbidade administrativa, então, em uma compreensão perfunctória, pode ser tida como a expressão adotada para descrever a corrupção pública, responsável pela promoção do desvirtuamento da Administração Pública (FIGUEIREDO, 2010), sendo corrupto aquele que se afasta dos critérios morais consagrados na sociedade, a fim de obter benefício privado em desfavor do interesse público (FERREIRA FILHO, 2001). Na lição de José Afonso da Silva (2010, p. 385), "o improbo administrativo é o devasso da Administração Pública”.

Sob esse prisma, entende-se a improbidade administrativa como uma ilegalidade qualificada por uma imoralidade consubstanciada na desonestidade do agente, conforme explicita Márcio Cammarosano (2006, p. 273):

Se digo que a imoralidade administrativa é um pluscom relação à legalidade, afirmo que a improbidade é o degrau seguinte. É a ilegalidade mais do que especialmente qualificada. Há uma gradação evidente entre estes comportamentos: existem atos ofensivos à ordem jurídica; existem outros atos que, além de ofensivos à ordem jurídica, ofendem valores morais juridicizados (caracterizada a ofensa à moralidade administrativa) e existem imoralidades administrativas de tal porte que merecem ser qualificadas como improbidade administrativa. 
Portanto, verifica-se que a improbidade administrativa se configura nas práticas fundadas na má-fé do sujeito ativo e que agridem deveres jurídicos estruturantes da Administração Pública, os quais, por sua vez, agasalham valores morais consagrados na sociedade e coletados pelo Direito para proteção específica, notadamente a legalidade, a moralidade e a probidade.

\section{OS ATOS DE IMPROBIDADE ADMINISTRATIVA}

A probidade administrativa é concepção resguardada, explicitamente, em solo constitucional, em especial nos arts. 14, $\S 9 \circ$ (que prevê a edição de lei complementar para estabelecer casos de inelegibilidade a fim de proteger a probidade administrativa), 15, inciso $\mathrm{V}$ (que prevê a possibilidade de perda ou suspensão de direitos políticos como sanção à improbidade administrativa), 37, § 40 (que prevê sanções à improbidade administrativa, na forma e na gradação de lei a ser editada), e 85, inciso V (que prevê como crime de responsabilidade do Presidente da República a prática de atos que atentem contra a probidade administrativa), todos da Constituição da República Federativa do Brasil.

Nesse diapasão, cumpre ressaltar o contido no art. 37, § $4^{\circ}$, da Carta Constitucional, dispositivo este que legou ao legislador infraconstitucional o dever de definir os comportamentos qualificáveis como improbidade administrativa, valendo-se, por certo, dos parâmetros fixados na sistemática constitucional, a qual previu, desde logo, determinadas sanções aos praticantes de atos ímprobos.

Assim, deu-se a criação da Lei n8.429, de 03 de junho de 1992 (Lei de Improbidade Administrativa), que, mesmo tendo inovado em inúmeras questões, não se constituiu em novidade absoluta na temática, vez que o ordenamento jurídico nacional já comportava duas(2) legislações anteriores na área, a saber: a) a Lei n³.164/1956 (Lei Pitombo-Godói Ilha), que tratava da sujeição do servidor público ao sequestro de bens adqui- 
ridos por influência ou abuso de cargo ou função pública ou de emprego em entidade autárquica, sem prejuízo de eventual responsabilidade criminal; e b) a Lei n 3.502/1958 (Lei Bilac Pinto), que abordava o sequestro e a perda de bens do servidor público da Administração Pública direta e indireta na hipótese de enriquecimento ilícito, por influência ou abuso de cargo ou função.

Ora, para que os agentes possam ser responsabilizados por atos de improbidade administrativa, faz-se necessário haver prévia e expressa previsão legal das condutas ilícitas. Caso contrário, a eventual punição consistiria em violação aos princípios da reserva legal (art. $5^{\circ}$, caput e inciso II, da Constituição da República Federativa do Brasil), da anterioridade (art. $5^{\circ}$, inciso XXXIX, da Constituição da República Federativa do Brasil) e da segurança jurídica (art. 5, caput e inciso XXXVI, da Constituição da República Federativa do Brasil).

A legalidade, inicialmente, consubstancia um pressuposto do Estado de Direito, perfazendo-se numa das principais garantias de respeito aos direitos individuais, decorrendo da lei a vontade da Administração Pública. Quanto à anterioridade, em analogia ao aforismo latino, de caráter penal, do nullumcrimennullapoenasine lege, não há improbidade administrativa e, por consequência, a respectiva sanção, sem uma prévia definição legal do ato como tal. Por fim, a segurança jurídica é essência constitutiva do próprio Estado Democrático de Direito, permeando a integralidade do sistema constitucional (FIGUEIREDO, 2010).

Nesse norte, a Lei n8.429/1992 trouxe os atos de improbidade administrativa em sentido amplo, os quais se dividem, basicamente, em duas (2) categorias: a)atos de improbidade administrativa em sentido estrito ou puros, do art. 11, em seus 8 (oito) incisos - com o último, incluído pela Lei n¹3.019/2014, entrando em vigor em 10.8.2015 -, que são aqueles que ofendem exclusivamente a probidade administrativa, entendida esta como a integração dos princípios regentes da Administração Pública 
(art. 4\%), independente de enriquecimento ilícito ou lesão ao patrimônio público (art. 21, inciso I); e b) atos de improbidade administrativa qualificados pelo resultado, subdividindo-se estes em: b.1) atos de improbidade administrativa qualificados pelo enriquecimento ilícito, do art. $9^{\circ}$, em seus 12 incisos, independente de lesão ao patrimônio público (art. 21, inciso I); e b.2) atos de improbidade administrativa qualificados pela lesão ao patrimônio público, do art. 10, em seus 21 incisos - com os últimos seis(6),incluídos pela Lei $\mathrm{n}^{\circ}$ 13.019/2014, entrando em vigor em 1०.8.2015 -, sendo exigida a efetiva lesão ao patrimônio público (art. 21, inciso I) (FAZZIO JÚNIOR, 2012).

Por fim, a despeito da consagração específica de inúmeras modalidades em cada uma das categorias previstas, tem-se entendido, tanto na doutrina ${ }^{3}$ quanto na jurisprudência ${ }^{4}$, que as hipóteses são meramente exemplificativas(numerusapertus), em especial pelo advérbio "notadamente" utilizado na enunciação dos dispositivos, de modo a ser dado ao operador do Direito poder enquadrar outras condutas, que não as ali previstas, como ímprobas.

\section{OELEMENTOSUBJETIVODOSATOSDEIMPROBIDADE ADMINISTRATIVA}

No direito contemporâneo, assentou-se a compreensão de que a imputação jurídica de um resultado danoso, para além de um vínculo causal objetivo, exige, como regra, a configuração de um fator subjetivo de ligação psíquica que o vincule ao agente, ressalvadas as hipóteses excepcionais expressamente previstas no ordenamento jurídico de responsabilização objetiva (GARCIA; ALVES, 2013).

3 PAZZAGLINI FILHOet al.Improbidade administrativa. 2. ed. São Paulo: Atlas, 1997. p. 57.

4 BRASIL. Superior Tribunal de Justiça. Recurso Especial n. 435.412/RO. Relatora Ministra Denise Arruda, Primeira Turma, julgado em 19.9.2006; BRASIL. Superior Tribunal de Justiça. Recurso Especialn ${ }^{\circ}$ 1.130.318/SP. Relator Ministro Herman Benjamin, Segunda Turma, julgado em 27.4.2010. 
No que tange à improbidade administrativa, especificamente, verifica-se que o art. $37, \S 6^{\circ}$, da Carta da Nação, mesmo consagrando a responsabilidade objetiva do Estado, preserva a responsabilidade subjetiva do agente público, dizendo que este só responde nos casos de dolo e culpa. Com base em tal disposição normativa, assim infere Fábio Medina Osório (2007, p. 436):

[...] creio que, ao adotar-se, na própria CRFB, a exigência de dolo ou culpa para embasar a ação de regresso, se está a consagrar o respaldo para reconhecimento do princípio da culpabilidade no campo punitivo, a partir de uma analogia com a responsabilidade subjetiva e não objetiva do agente público para mero ressarcimento ao erário. A responsabilidade deste se diferencia da responsabilidade objetiva do Estado. Há, portanto, um indicativo de que, noutras situações mais severas, nas quais está envolvido o poder sancionador do Estado, e não a pretensão de restituição, é necessário reconhecer e respeitar as exigências inerentes ao princípio da culpabilidade, na modalidade de uma responsabilidade mais acentuadamente comprometida com os vetores do sistema punitivo.

Dessarte, inegável é reconhecer a indispensabilidade da presença de um elemento subjetivo no agir do agente para a configuração do ato de improbidade administrativa.

Nesse esteio, tem-se que o elemento subjetivo representativo do elo entre a vontade, a conduta e o resultado, em regra, pode-se apresentar sob duas(2) formas genéricas distintas, quais sejam, o dolo e a culpa (GARCIA; ALVES, 2013).

Segundo Emerson Garcia e Rogério Pacheco Alves (2013, p. 401-402), "entende-se por dolo a vontade livre e consciente dirigida ao resultado ilícito, ou mesmo a mera aceitação do risco de produzi-lo", sendo que "a culpa, por sua vez, se caracteriza pela prática voluntária de um ato sem a atenção ou o cuidado normalmente empregados para prever ou evitar o resultado ilícito". 
No caminhar, referem-se os autores, ainda, às lições de Nelson Hungria (1983 apud GARCIA; ALVES, 2013, p. 402), para quem, "no dolo, ação (ou omissão) e resultado são referíveis à vontade; na culpa, de regra, somente a ação (ou omissão)", bem como de Francesco Carrara (1956 apud GARCIA; ALVES, 2013 , p. 402), segundo o qual "a incorreção representada pelo dolo provém da fraqueza da vontade, e a incorreção que a culpa representa provém da debilidade do intelecto", sendo que "o não ter previsto a consequência ofensiva distingue a culpa do dolo".

Quanto aos atos de improbidade administrativa, em leitura à Lei no 8.429/1992, constata-se que os arts. 9० (atos de improbidade administrativa qualificados pelo enriquecimento ilícito) e 11 (atos de improbidade administrativa em sentido estrito ou puros) nada mencionam quanto ao elemento subjetivo exigivel, fazendo-o apenas o art. 10 (atos de improbidade administrativa qualificados pela lesão ao patrimônio público), o qual estabelece, expressamente, ser possível a prática dos atos nele previstos tanto por dolo quanto por culpa, o que levou a Corte Especial do Superior Tribunal de Justiça, após inúmeras discussões e divergências, a consagrar o seguinte entendimento:

Não se pode confundir improbidade com simples ilegalidade. A improbidade é ilegalidade tipificada e qualificada pelo elemento subjetivo da conduta do agente. Por isso mesmo, a jurisprudência do STJ considera indispensável, para a caracterização de improbidade, que a conduta do agente seja dolosa, para a tipificação das condutas descritas nos artigos $9^{\circ}$ e 11 da Lei 8.429/92, ou pelo menos eivada de culpa grave, nas do artigo $10^{5}$.

Todavia, os atos de improbidade administrativa, em sua acepção basilar, fulcram-se na má-fé do sujeito ativo, em sua desonestidade, que é o elemento de imoralidade que qualifica

5 BRASIL. Superior Tribunal de Justiça. Ação de Improbidade Administrativa n. 30/ AM. Relator Ministro Teori Albino Zavascki, Corte Especial, julgada em 21.9.2011. 
a ilegalidade e, por consequência, configura o agir ímprobo e enseja a punição respectiva (CAMMAROSANO, 2006; FAZZIO JÚNIOR, 2012).

Ora, a improbidade tem por premissa de configuração a ocorrência de um desvio ético do agente, praticado de modo a, consciente e voluntariamente, transgredir determinação cujo atendimento era obrigatório, ou seja, de forma volitiva e pré-ordenada, violam-se, especificamente, normas jurídicas previstas à proteção da Administração Pública, com ciência do sujeito ativo quanto ao resultado atentatório à probidade administrativa decorrente de seu agir (FIGUEIREDO, 2010).

Com efeito, o objetivo da Constituição Federal e, por consequência, da Lei no 8.429/1992, diante da concepção do que configura, como anteriormente declinado, o ato de improbidade administrativa, é punir, por ofensa à legalidade, à moralidade e, sobretudo, à probidade, o indivíduo desonesto, imbuído de má-fé em suas práticas, e não aquele incompetente ou mesmo inábil de boa-fé (FIGUEIREDO, 2010; PAZZAGLINI FILHO, 2006), não se podendo, de modo algum, tomar mera inabilidade como um sinônimo de desonestidade (MATTOS, 2005).

Por essa razão, consoante Aristides Junqueira Alvarenga (2001, p. 108):

[...] torna-se difícil, se não impossível, excluir o dolo do conjunto de desonestidade e, consequentemente, do conceito de improbidade, tornando-se inimaginável que alguém possa ser desonesto por mera culpa, em sentido estrito, já que ao senso de desonestidade estão jungidas as ideias de má-fé, de deslealdade, a detonar o dolo.

Em mesmo sentido, calha a lição de Isabela Giglio Figueiredo (2010, p. 128), para quem, ao se aceitar a modalidade culposa:

[...] estar-se-ia a admitir que quaisquer ilícitos sejam erigidos em ilegalidades configuradoras de infrações à Lei de Improbidade, confundindo, pois, 
o espírito punitivo da lei, que se dirige ao agente público desonesto e corrupto, que atua com dolo, e não àquele incompetente, despreparado, desorganizado.

Apesar do consagrado postulado hermenêutico segundo o qual não existem palavras inúteis na lei, numa interpretação lógica e sistemática do texto constitucional e daquele da Lei ${ }^{\circ}$ 8.429/1992, não se faz possível extrair conclusão outra senão a de que somente o elemento subjetivo doloso perfaz o corpus delicti do ato de improbidade administrativa, inadmitindo-se, à evidência, a versão culposa, sob pena de se malferir o intuito da norma, a qual se destina, impreterivelmente, à punição da desonestidade e da má-fé (FIGUEIREDO, 2010).

Sob esse prisma, inegável é reconhecer que a expressão culposa prevista no caput do art. 10 da Lei no 8.429/1992, enquanto elemento subjetivo apto à configuração de improbidade administrativa, é inconstitucional, notadamente por afrontar o art. 37, § 4º da Constituição da República, o qual relegou ao legislador infraconstitucional a definição dos comportamentos a ser considerados como ímprobos, bem como as respectivas sanções, em forma e gradação a seu talante, desde que ressalvados os parâmetros da sistemática constitucional, da qual se deflui, como acima visto, incontestadamente, a restrição de incidência das punições por improbidade administrativa às condutas imbuídas de má-fé, de desonestidade (MATTOS, 2005), elementos esses umbilicalmente ligados ao dolo e, assim, divorciados da culpa.

Portanto, claro está que a lei integradora transcendeu a vontade da norma constitucional ao levar o permissivo da Lei Fundamental para além dos limites nesta estabelecidos, expurgando do dispositivo legal, assim, a proporcionalidade e a razoabilidade exigíveis (FIGUEIREDO, 2000).

Dessa forma, parece cabível, porquanto necessária e pertinente, a declaração de inconstitucionalidade parcial sem redução de texto do caput do art. 10 da Lei n8.429/1992, o qual 
permanece incólume, apenas não mais se admitindo, porém, a aplicação do dispositivo no atinente à sua feição culposa, tornando-o mais consentâneo, inegavelmente, com a vontade constitucional (FIGUEIREDO, 2010).

Uma vez fixada a exclusividade do elemento subjetivo doloso, cumpre constatar em quais modalidades desta feição admite-se a configuração de improbidade administrativa.

De acordo com Damásio de Jesus (2011, p. 330-331), o dolo tem por principal classificação a distinção entre dolo direto ou determinado e dolo indireto ou indeterminado. No primeiro, "o sujeito visa a certo e determinado resultado", enquanto, no segundo, "a vontade do sujeito não se dirige a certo e determinado resultado".

O dolo indireto ou indeterminado, por sua vez, ainda segundo o autor, subdivide-se em dolo alternativo e dolo eventual. No primeiro, "a vontade do agente se dirige a um ou outro resultado", enquanto, no segundo, "o sujeito assume o risco de produzir o resultado, isto é, aceita o risco de produzi-lo", apesar de "não querer o resultado, pois, se assim fosse, haveria dolo direto", porém, "percebe que é possível causar o resultado e, não obstante, realiza o comportamento", afinal, "entre desistir da conduta e causar o resultado, prefere que este se produza".

No que atine aos atos de improbidade administrativa, enquanto essencial à sua configuração a existência de má-fé, de desonestidade do sujeito do ativo, de rigor que tal elemento esteja presente tanto na prática da conduta quanto no querer o resultado, pois, como lecionam Márcio Cammarosano e Flávio Henrique Unes Pereira (2013, p. 30), "de um comportamento voluntário (causa) não se pode concluir, ipso facto, necessariamente, que o resultado (efeito) tenha sido também querido direta ou indiretamente pelo agente".

Assim, na modalidade de dolo direto, bem como na de dolo indireto, tanto na feição alternativa quanto eventual, parece ser possível conceber a presença da desonestidade do sujeito ativo, tanto na conduta, quanto no resultado, afinal, 
uma vez querendo a conduta, ainda que apenas assuma o risco do resultado lesivo à Administração Pública, estando ciente da possível presença deste - permitindo, assim, com o seu agir, que venha a se concretizar a sua ocorrência -, suficientemente latente restará a sua má-fé, a sua desonestidade, na vontade inclinada ao resultado, ao menos em um nível apto a qualificar seu ato como ímprobo e, por consequência, autorizar a punição.

Logo, tem-se que os atos de improbidade administrativa, uma vez assentados na má-fé, por desonestidade, do sujeito ativo, item esse de imoralidade que qualifica a ilegalidade e caracteriza a improbidade, mostram-se incompatíveis com o elemento subjetivo da culpa, por não se punir a mera inabilidade, admitindo-se, assim, apenas o dolo, tanto direto quanto indireto, nas modalidades alternativa e eventual, porquanto age de má-fé não apenas aquele que efetivamente quer um ou mais resultados, de forma direta ou alternativa, mas também o que assume, voluntariamente, o risco consciente de sua eventual ocorrência.

\section{CONCLUSÃO}

A corrupção é fenômeno há muito existente na sociedade brasileira, com aprimoramento, ao longo do tempo, tanto, de um lado, de suas práticas, quanto, de outro, dos mecanismos de repressão e do rigor punitivo.

Nesse sentido, a Constituição da República Federativa do Brasil, em 1988, consagrou uma série de princípios regentes da Administração Pública, prevendo, dentre as medidas para sua efetivação, no art. 37, § 4\%, a punição dos atos de improbidade administrativa, em força e gradação a ser definidas em lei, providência esta tomada com a edição da Lei no 8.429/1992, que veio disciplinar tais atos, os seus requisitos de configuração e as sanções aplicáveis.

A improbidade, por sua vez, em sua origem conceitual, relaciona-se a concepção de desonestidade, de má-fé do sujeito, um atributo negativo da personalidade e do caráter humano. 
Quando ligada à Administração Pública, porém, a improbidade excede à moral genérica, alcançando a moral jurídica, pois passa a não mais violar apenas um dever moral, mas também um dever legal, por mácula a preceitos consagrados no ordenamento jurídico nacional em favor do Estado. Por essa razão, faz-se possível descrever a improbidade administrativa como uma ilegalidade qualificada pela imoralidade do sujeito, consubstanciando-se esta na sua má-fé, na sua desonestidade, em desprestígio à Administração Pública.

Com efeito, a improbidade administrativa, seguindo o preceito constitucional, vem disciplinada na Lei nº.429/1992, a qual, porém, não constituiu verdadeira inovação no âmbito da punição da prática e dos valores que seu sancionamento busca resguardar, eis que já existentes no ordenamento pátrio normas prévias sobre a temática - Leis no 3.164/1956 (Lei Pitombo-Godói Ilha) e n³.502/1958 (Lei Bilac Pinto) -, ainda que de aplicação mais restrita.

Os atos de improbidade administrativa, a seu turno, vêm previstos nos arts. $9^{\circ}$ a 11 da Lei no $8.429 / 1992$, em suas diversas categorias, ainda que em umrol exemplificativo, com as respectivas sanções cabíveis, afinal, faz-se necessário previamente disciplinar as condutas ilícitas e suas punições para que possível as aplicar, isso em homenagem aos princípios constitucionais da reserva legal, da anterioridade e da segurança jurídica.

Sob esse prisma, ainda, vê-se que se assentou, no direito contemporâneo, a necessidade de um elemento psíquico do sujeito para que lhe sejam imputadas as consequências de um evento danoso, para além de um liame objetivo de causalidade, ressalvadas hipóteses expressas de responsabilização objetiva.

Diversa não é a situação dos atos de improbidade administrativa, notadamente pelo princípio da culpabilidade consagrado no art. 37 , § $6^{\circ}$, da Lei Fundamental, sendo inegável, portanto, exigir a presença de um elemento subjetivo para a configuração daqueles. 
A concepção do ato de improbidade administrativa, por sua vez, enquanto agir imbuído de má-fé, a despeito da consagração, no art. 10 da Lei no 8.429/1992, da modalidade culposa, parece com esta não se compatibilizar, estando, em verdade, umbilicalmente ligado ao dolo, afinal, a prática que se pretende punir, à evidência, é aquela decorrente de desonestidade, e não de mera inabilidade, sob pena de descaracterização do próprio conceito de improbidade e, ainda, violação ao preceito constitucional que determina a sua punição.

Por fim, estabelecida a exclusividade do elemento subjetivo doloso à configuração da improbidade administrativa, verifica-se que é identificável a má-fé, a desonestidade, tanto do sujeito que, ao agir, quer, efetivamente, a ocorrência de um ou mais resultados, quanto daquele que assume o risco de sua ocorrência, pelo o que suficientes ao preenchimento do dolo exigido pela improbidade administrativa tanto o direito quanto o indireto, este em suas modalidades alternativa e eventual.

\section{REFERÊNCIAS}

ALVARENGA, Aristides Junqueira. Reflexões sobre improbidade administrativa. In: BUENO, Cássio Scarpinella; PORTO FILHO, Pedro Paulo de Rezende (Coord.). Improbidade administrativa: questões polêmicas e atuais. São Paulo: Malheiros Editores, 2001.

BRASIL. Congresso Nacional. Constituição da República Federativa do Brasil. 5 out. 1988.

BRASIL. Congresso Nacional. Lei n. 13.019/2014. 31 jul. 2014.

BRASIL. Congresso Nacional. Lei n. 3.164 (Lei Pitombo-Godói Ilha). 1 jun. 1956.

BRASIL. Congresso Nacional. Lei n. 3.502 (Lei Bilac Pinto). 21 dez. 1958.

BRASIL. Congresso Nacional. Lei n. 8.429 (Lei de Improbidade

Administrativa). 2 jun. 1992. 
BRASIL. Superior Tribunal de Justiça. Ação de Improbidade Administrativa n. 30/AM. Relator Ministro Teori Albino Zavascki, Corte Especial, julgada em 21.9.2011.

BRASIL. Superior Tribunal de Justiça. Recurso Especial n. 1.130.318/ SP. Relator Ministro Herman Benjamin, Segunda Turma, julgado em 27.4.2010.

BRASIL. Superior Tribunal de Justiça. Recurso Especial n. 435.412/RO.

Relatora Ministra Denise Arruda, Primeira Turma, julgado em 19.9.2006.

CAMMAROSANO, Márcio; PEREIRA, Flávio Henrique Unes. Improbidade administrativa e a jurisprudência do STJ:o esvaziamento do dolo nos arts. $9^{\circ}$ e 11, e a inconstitucionalidade da culpa no art. 10. Revista CEJ - Conselho da Justiça Federal, Brasília, v. 17, n. 61, set./dez. 2013, p. 115-121.

CAMMAROSANO, Márcio. O princípio constitucional da moralidade e o exercício da função administrativa. Belo Horizonte: Fórum, 2006.

FAZZIO JÚNIOR, Waldo. Improbidade administrativa:doutrina, legislação e jurisprudência. São Paulo: Atlas, 2012.

FERREIRA FILHO, Manoel Gonçalves. A democracia no liminar do século XXI. São Paulo: Saraiva, 2001.

FIGUEIREDO, Isabela Giglio. Improbidade administrativa: dolo e culpa. São Paulo: QuartierLatin, 2010.

FIGUEIREDO, Marcelo. Probidade administrativa. 4. ed. São Paulo: Malheiros Editores, 2000.

GARCIA, Emerson; ALVES, Rogério Pacheco. Improbidade administrativa. 7. ed. rev., ampl. e atual. São Paulo: Saraiva, 2013.

MATTOS, Mauro Roberto Gomes de. O limite da improbidade administrativa:o direito dos administrados dentro da Lei n. 8.429/1992. 2. ed. rev., atual. eampl. Rio de Janeiro: América Jurídica, 2005.

MOREIRA NETO, Diogo de Figueiredo. Curso de direito administrativo. 15. ed. Rio de Janeiro: Forense, 2009.

NEVES, Daniel Amorim Assumpção; OLIVEIRA, Rafael Carvalho Rezende. Manual de improbidade administrativa: direito material e processual. 2. ed. rev., atual. e ampl. Rio de Janeiro: Forense; São Paulo: Método, 2014. 
OSÓRIO, Fábio Medina. Direito administrativo sancionador. 2. ed. São Paulo: Revista dos Tribunais, 2007.

PAZZAGLINI FILHO, Marinoetal.Improbidade administrativa. 2. ed. São Paulo: Atlas, 1997.

PAZZAGLINI FILHO, Marino. Lei de improbidade administrativa comentada: aspectos constitucionais, administrativos, civis, criminais, processuais e de responsabilidade fiscal; legislação e jurisprudência atualizadas. 3. ed. São Paulo: Atlas, 2006.

ROCHA, Cármen Lúcia Antunes. Improbidade administrativa e finanças públicas. Boletim de direito administrativo, dez. 2000.

SILVA, José Afonso. Curso de direito constitucional positivo. 33. ed. rev. e atual. São Paulo: Malheiros Editores, 2010.

SILVA, Oscar Joseph de Plácido e. Vocabulário jurídico. Rio de Janeiro: Forense, 1987.

Artigo recebido em 17/06/2015

Artigo aprovado em 27/08/2015 